\title{
Multicriteria strategic approach for the selection of concrete suppliers in a construction company in Colombia
}

\author{
Autores \\ Jorge E. Restrepo, Dionicio Neira Rodado, Amelec Viloria Silva
}

\begin{abstract}
Within companies of the construction sector, the evaluation and selection of concrete suppliers, is considered a fundamental topic for the adequate construction of buildings, due to the impact it has, not only in the stability of the building but also in the productivity and the profitability. For an adequate selection, decision-makers must consider a series of criteria of different kind. However, as in different fields, due to the numerous criteria and alternatives that should be considered in the construction industry, the choice of an appropriate multicriteria decisionmaking approach has become a critical step in the selection of suppliers. Therefore, the objective of this research is to define the most adequate supplier of suitable concrete through the integration of powerful multicriteria decision-making methods. For this purpose, a fuzzy analytical hierarchy process (FAHP) is initially applied to define initial factor weights under uncertainty, followed, using the decision-making test and the evaluation laboratory (DEMATEL) to evaluate the interrelationships between elements of the hierarchy. Then, after combining FAHP and DEMATEL to calculate the final contributions of the factors including the interdependence, finally TOPSIS technique is used for the order of preference for the similarity with the ideal solution to evaluate and determine the best supplier.
\end{abstract}

Palabras clave

Construction, industry, DEMATEL AHP, Selection of suppliers. 